\title{
Effective Project Management: A Knowledge Management And Organizational Citizenship Behavior Approach
}

\author{
Robert F. Cope III, (E-mail: rcope2@selu.edu), Southeastern Louisiana University \\ Rachelle F. Cope, (E-mail: rcope@selu.edu), Southeastern Louisiana University \\ Teri L. Root, (E-mail: troot@ selu.edu), Southeastern Louisiana University
}

\begin{abstract}
In the current complex business environment, projects are viewed as critical building blocks for organizational success. In fact, there seems to be a powerful interaction between the flow of project work and the flow of knowledge in an organization. Such interaction leads to the exploration of the concept of effective Knowledge Management strategies for Project Management based on the guiding principles of Organizational Citizenship Behavior. In the past, Knowledge Management has been thought of as the collection of technological assets and managerial policies that compensate for information failures. Recent studies have uncovered the popularity of Knowledge Management research since most project environments have the potential, but do not promote personal information sharing.
\end{abstract}

\section{INTRODUCTION}

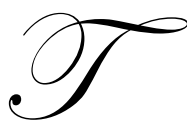

oday, almost every organization is involved in projects, leading several business executives and experts to declare that 'Project Management is the wave of the future.' Stewart (1996) proclaims that the corporate jungle has a new species, the project manager, who will fill the void created by the extinction of middle management. More and more firms are realizing that managing projects, as well as project teams, can be a vital part of everyone's job.

The concept of Knowledge Management (KM) has been around for decades, but most organizations accept it only as theory and have not put it into practice. It has been difficult for many organizations to evolve their organizational thinking from an information focus to a knowledge focus. Throughout the past several decades, Information Systems practices were sufficiently developed to accomplish efficient production of information. Problems arose when information was in abundance, but key individuals possessing that information did not or would not share it with others who stand to benefit from its discovery.

In our work, we explore the topic of KM in the context of project-oriented businesses. Recent studies have centered on how project managers might use KM to enhance or create more effective project environments. Of particular interest is the need to examine KM practices to compensate for deficits in tacit knowledge (project manager/task leader centered). Thus, we explore the view of enhancing project organization productivity by identifying common practices that would lead to the widespread deployment of knowledge. Strategies are proposed based on the relationships between KM and Organizational Citizenship Behavior (OCB), as well as the development of a potential reward system for information sharing. 


\section{PROJECT MANAGEMENT, ORGANIZATIONS AND TEAMS}

Project Management (PM) has long been associated with Operations Management, and is an important topic in the Operations Management curriculum. By definition, a project is a complex, non-routine, one-time effort limited by time, budget, resources, and performance specifications designed to meet customer needs (Gray and Larson, 2006). It can also be viewed as a set of temporary activities conducted by an ad hoc organization (Olson, 2004).

Organizations that support such non-routine, one-time efforts are known as project organizations, where functional lines of authority are not key to organizational success. The project organization is a setting that is highly conducive to innovation, since new products and processes evolve from new ideas discovered during cross-functional, team-working interaction. This type of environment is often viewed as a vehicle for change and improvement, generally resulting in significant benefits for the firm. Unfortunately, the one-time efforts and ad hoc arrangements of projects often lead to lost or hoarded knowledge.

Project organizations are generally composed of many project teams carrying out several projects for an organization at once. Project teams are groups of people with the unique, specialized skills that come together to accomplish a particular assignment. The core of a project team includes the roles of project manager, task leaders and project expediters (or coordinators). Table I describes the responsibilities of each team member.

Table I

Common Project Team Roles

\begin{tabular}{|c|l|}
\hline Project Team Role & \multicolumn{1}{c|}{ Description } \\
\hline Expeditor & An individual who monitors problems in an organization and works on alleviating them rapidly. \\
\hline Task Leader & A person of certain skill whose purpose is to coordinate work efforts to accomplish a specific task. \\
\hline Project Manager & An individual assigned the responsibility of accomplishing project objectives. \\
\hline
\end{tabular}

\section{TRENDS IN PROJECTS}

Although projects are defined as one-time efforts, there are many common, yet repeatable tasks performed within them. As a technological example, we have all witnessed the changes that have occurred in computer programming through time. In the early years, programs were written specifically for the task at hand. In later years, programs similar in development were interchanged and modified (repeated) to meet different customer needs. Today, computer program modules are written and stored in libraries so programmers can utilize what they need to meet customer requirements.

In addition, academic research projects are also excellent examples of projects that are most frequently conducted on an ad-hoc basis to achieve specific objectives. In fact, there are enough commonalities from research project to research project that many academicians would likely describe their research as a process consisting of a series of successive steps. Granted not every project will complete every single step, nor will every project follow the steps in the exact order.

In support of the research example, Burns and Bush (2006) contend that conceptualizing marketing research projects as a series of successive steps has merit. It provides marketing researchers and non-researchers with an overarching framework in which to view the entire research process. It may also provide guidance or direction to the researcher(s) in terms of which tasks may need to be accomplished and in what order.

\section{AN ADVERTISING EXAMPLE}

One example is that of an advertising campaign. Integrated Marketing Communication (IMC) campaigns generally include the following components: Situation Analysis, SWOT Analysis, Campaign Strategy, Communication Strategy, Media Plan, Budget Appropriation and Campaign Evaluation (Wells, et. al, 2003). A 
company utilizing such a practice to introduce a new product may consider its promotion unique, but more than likely, many of the IMC tasks have been done before for other campaigns. For many, learning has already taken place, knowledge has been gained, and future projects become simpler to perform utilizing the repeated tasks. As an illustration, an outline of some of the common steps involved in developing an advertising campaign is explored.

One of the first steps in an advertising campaign is to conduct a situation analysis. A situation analysis is a "condensed review of pertinent elements presented in the marketing plan" (Arens, 2006). In a situation analysis, one would typically find a description of the following elements of the marketing plan:

1. The current marketing situation for the company/brand.

2. A description of the target market(s) and characteristics/descriptors (e.g. demographic, geographic, psychographic, usage rate, etc) of those target markets.

3. A specification of the marketing objectives for the company/product/service.

4. A summarized presentation of the marketing mix (e.g. product, price, distribution, and communication plans) for each target market.

5. An indication of how advertising fits into the communication plan.

Essentially, the situation analysis provides valuable background information that enables the firm to identify its internal strengths and weaknesses and its external opportunities and threats (commonly referred to as a SWOT analysis). The advertising manager (and/or project team) must then decide for a particular campaign which strengths and opportunities should be capitalized on and/or which weaknesses and threats should be addressed. In other words, what they hope to achieve at the end of the campaign process. For advertising to be effective, these objectives should be specific, realistic, and measurable. The SWOT analysis is one task that is undertaken on a project by project basis, yet it consists of repeatable tasks.

Many large companies have in-house advertising departments, but they also rely on external advertising agencies. While some companies hire multiple advertising agencies, the largest firms typically have "an agency of record." In the case where a company is utilizing an outside advertising agency, an account executive from the advertising agency serves as a liaison between the agency and the client. Personnel from the advertising department of the client firm serve as representatives for that firm. They are critical in providing the necessary background information (the situation/SWOT analysis) and in developing meaningful objectives for the campaign.

Traditionally, the account executive represents the client to the agency's creative team by providing the necessary background information and objectives for a particular campaign. Today, many of the most successful advertising agencies are recognizing that additional research and insights are needed regarding consumer needs, behaviors, and relationships with companies, products, and brands. The account planner bridges the gap between account management and the creative function of the agency. Account planning is "a hybrid discipline that bridges the gap between traditional research, account management, and creative direction whereby agency people represent the view of the consumer in order to better define and plan the client's advertising program" (Arens, 2006). Account planners conduct additional consumer research through quantitative research methods such as surveys but more so, through qualitative research techniques such as focus groups and personal interviews. Although the questions asked of consumers are likely to be tailored to a particular client's situation, the process of collecting such data is likely to consist of steps that have been repeatedly applied to other projects.

The account planners then work with the creative team to translate their findings into effective and imaginative advertisements. The creative team consists of copywriters who create the verbal content of advertisements and art directors, graphic designers, and production artists who create the visuals which will convey what is being communicated nonverbally through the advertisement. The creative team works under a creative director. For any particular project, the creative team and director may approach the creative process using techniques such as brainstorming that have been utilized for other projects as well. During this phase of the campaign, advertising research may be used to pre-test different creative aspects of the advertisements. Again, while the subject matter of the research varies from project to project, common pre-testing methodologies are likely to be applied and repeated across multiple projects. 
Upon approval of the client, the ad is then turned over to the agency's production department. Some of the production may be done in-house, while some may be outsourced to suppliers which are organizations that provide specialized services in the advertising industry such as art studios, printers, and independent production houses. The production phase of the advertising campaign will most likely consist of a series of repeatable steps.

Media planning and buying decisions may be made concurrently with creative decisions. Today media planning is critical for a number of reasons:

1. It is the mode of communication for the campaign.

2. Audiences are highly fragmented today; there is a proliferation of media options.

3. $\quad$ Companies are faced more and more with constrained budgets.

4. Traditional media options offer less reach (e.g. number of people exposed to an ad at least once during a campaign) at higher rates than in the past.

For the aforementioned reasons and more, media planning is much more complex in today's environment. Consequently, advertising agencies may perform media services for their clients such as research, negotiating, scheduling, buying and verifying. These changes in the media market have also created a need for media specialty companies. The traffic department of an advertising agency coordinates production and media buying making sure deadlines are met. As with the other aspects of the advertising campaign, the process of acquiring media and the process of keeping track of deadlines is likely to have some routine, repeatable steps and processes.

The final stage of the campaign is to evaluate the campaign itself to determine whether it has successfully met its objectives. This stage involves post-testing research that may utilize some of the same research techniques applied in pre-testing the creative concepts.

In sum, the knowledge gained by performing repeatable tasks is often a by-product of the PM process. But, if captured, such information can lead to more effective PM. Therefore, if PM as a whole has the same destiny as the computer programming, academic research and advertising examples, then KM is the vehicle to get us there.

\section{KNOWLEDGE MANAGMENT}

Dunn and Neumeister (2002) provide a synopsis of the evolution of Knowledge Management. They postulate that instances of KM may have first been recognized around the time of World War II. It was during this time that it became evident how workers learned from experience. For instance, it was noticed that building a second airplane took considerably less time than building the first. Nobel Prize-winning economist Kenneth Arrow (1962) addressed the issue of learned experience (i.e. KM) in his article entitled "The Economic Implications of Learning by Doing." It was during this same time period that resources began to be devoted to the cause of determining significant performance variations in output within organizations. Although it is unclear when the term "Knowledge Management" was officially coined, its concept intensified in the 1990s. Karl Wiig (1993) authored "Knowledge Management Foundations: Thinking about Thinking - How People and Organizations Create, Represent and Use Knowledge" which was possibly the first published use of the term.

Dunn and Neumeister (2002) define Knowledge Management as a systematic approach to managing and leveraging an organization's knowledge assets, which may include knowledge of the organization's customers, products, markets, processes, finances and personal services. Novins (2002) shortens the definition to simply say KM can be thought of as packaging the right content and delivering it to the right people who can make use of it at the right time. Koskinen's (2004) work categorizes KM into two components to support communication and implementation in management. First, he defines explicit knowledge as knowledge that can be embodied in a code or a language, and, as a consequence, can be communicated easily. The code may be words, numbers, or symbols like grammatical statements, mathematical expressions, specifications, manuals, and so forth. In addition, he defines tacit knowledge as knowledge based on the experience of individuals. It expresses itself as human actions in the form of evaluations, attitudes, points of view, commitments, motivation, etc. Some have summarized tacit knowledge by the 
phrase, "We know more than we can tell." To distinguish between the two, explicit knowledge is about why things work, and tacit knowledge is about what things work.

\section{ISSUES IN PROJECT MANAGEMENT}

The growth in new knowledge and technology has increased the complexity of projects since they generally encompass the latest advances. With that caveat in mind, projects are generally assessed along three dimensions: Time, Cost and Quality, and each dimension can be influenced by the latest knowledge and technological advances. Because of this inherent trait in projects, Olson (2004) argues that most projects will meet any two of the dimensions, but very few meet all three. This, in turn, affects the five M's of projects: material, manpower, machinery, money and methodology. Table II below lists and describes these major internal issues encountered by project managers, leading many to miss important project dimensions.

Table II

Issues Surrounding the Five "M's" of Project Management

\begin{tabular}{|c|l|c|}
\hline Issue & \multicolumn{1}{|c|}{ Description } & Most Affected Dimension \\
\hline Material & $\begin{array}{l}\text { Inferior supplies and poor inventory practices for tasks and other basic project } \\
\text { needs. }\end{array}$ & Quality \\
\hline Manpower & $\begin{array}{l}\text { Inexperienced labor, lack of loyalty and organizational goals, poor } \\
\text { communication and training, etc. }\end{array}$ & Time \\
\hline Machinery & Poor technology choices and/or availability for tasks. & Time \\
\hline Money & Lack of funding or failure of market to develop for final deliverable. & Cost/Quality \\
\hline Methodology & $\begin{array}{l}\text { Poor marketing research, inadequate technological design, poor project } \\
\text { structure, use of outdated processes and procedures, excessive change orders, } \\
\text { etc. }\end{array}$ & \\
\hline
\end{tabular}

Interviews with PM professionals have uncovered some of the challenges in managing "cutting edge" projects. Pressures to complete them in short amounts of time often present project scope problems. Some consultants have reported that many projects are generally given a brief planning period followed by extensive design and development time to meet due dates. This technique often requires several iterations of project change orders requiring extra production time and increased costs before customers agree on and accept a completed project. It can be a difficult cycle to terminate.

\section{KNOWLEDGE MANAGEMENT BENEFITS}

Thus far, KM has been presented as a practice that makes sense for improving PM. It is the concept of combining the expertise, wisdom and insights of those individuals who have come to their wisdom the hard way. If the wisdom could be captured and shared within the PM community, it would make sense that organizations would benefit infinitely. Such benefits occur in both explicit and tacit forms. For example, explicit KM benefits include but are not limited to:

1. Data collection on completed work packages, milestones, and projects can be obtained.

2. Interdependencies among tasks due to shared resources can be addressed.

3. Identification of real risks and the methods used to alleviate them can be determined.

Examples of tacit knowledge benefits include but are not limited to:

1. Interviews that can determine what processes/methods were successful.

2. Interviews that can also determine what actions (taken) did not work.

3. Quicker movement through a task or project's learning curve. 


\section{APPLYING KNOWLEDGE MANAGEMENT TO THE ISSUES}

In summarizing the characteristics of KM, Peter Novins (2002) postulates that good KM should have three characteristics. First, it needs to address a real business problem that everybody agrees is a problem. Second, an organization cannot sustain a KM system without some kind of community interest or practice that provides content and accepts responsibility for continuing to build and share the content. Third, KM systems have to make it very, very easy for people to get the content they need.

In addition, O'Dell (2004) describes the three roles necessary for a successful KM system. These roles are identified and defined in Table III. To effectively apply these roles, it is important for organizations to realize that KM will not happen without sufficient technological resources. Such resources should be dedicated to the task of making information sharing possible.

Table III

Roles for successful KM Systems

\begin{tabular}{|l|l|}
\hline \multicolumn{1}{|c|}{ KM Roles } & \multicolumn{1}{c|}{ Description } \\
\hline Knowledge Steward & One who collects, analyzes and organizes knowledge held by individuals within an organization. \\
\hline Knowledge Facilitator & One who establishes connections between individuals in order to share knowledge. \\
\hline $\begin{array}{l}\text { Community of Practice } \\
\text { Leader }\end{array}$ & $\begin{array}{l}\text { One who sets the direction and climate for knowledge sharing in the community and ensures that } \\
\text { the organization and the members are all benefiting from the exchange. }\end{array}$ \\
\hline
\end{tabular}

In PM, the most profound aspect of KM is that, ultimately, an organization's only sustainable competitive advantage lies in what its employees know and how they apply that knowledge to projects. The addition of KM repositories to PM enhances an organization's ability to:

1. Think in broad terms.

2. Capture issues for study and/or observation.

3. Take independent remedies and address issues in an interdependent fashion.

4. $\quad$ Catch issues that have traditionally "slipped through the cracks."

Our proposed framework of role dependencies between PM and KM responsibilities is presented in Table IV. It is here that project organizations define and assign who will handle which issues and collect the corresponding explicit and tacit knowledge that will prepare others for more successful projects.

Table IV

Project Team Responsibilities/Assignments for Effective KM

\begin{tabular}{|c|c|c|c|}
\hline Project Team Role & Corresponding KM Role & Project Issues & Key KM Component \\
\hline Expeditor & Knowledge Steward & Material & Explicit \\
\hline Task Leader & Knowledge Facilitator & Manpower, Machine & Tacit \\
\hline Project Manager & Community of Practice Leader & Money, Methods & Tacit \\
\hline
\end{tabular}

\section{BARRIERS TO EFFECTIVE KNOWLEDGE MANAGEMENT}

Having explored the nature of $\mathrm{KM}$ as an important tool for project organizations, our research must also address barriers that inhibit its effectiveness. The question is: "How can project managers and team members be motivated to share the knowledge gained from their experiences?" The typical culture shared by many project managers is not one that rewards the sharing of ideas and wisdom. Promotion and job security are functions of a 
project manager's ability to generate original ideas, and apply them in unique ways. In such a case, knowledge can be though of as a belief that is justified and then internalized. Therefore, it can be lost, shared, or hoarded.

\section{ORGANIZATIONAL CITIZENSHIP BEHAVIOR}

The phrase "Organizational Citizenship Behavior" (OCB) was first used by Organ (1990) to denote organizationally beneficial behavior of workers that was not prescribed, but occurred freely to help others achieve the task at hand. OCB emphasizes the social context of the work environment in addition to the technical nature of the job. OCB has been defined in terms of pro-social behavior, altruism and service orientation. These behaviors are usually not monitored by the organization's reward system, but provide the organization with a long-term social advantage (Skarlicki and Latham 1995).

Research conducted in order to define the dimensionality of OCB in organizations has provided conflicting results. However, there appears to be support for a two-factor model to universally define OCB (Williams and Anderson 1991). The two factors are:

1. OCB that benefits the organization in general, such as a willingness to participate in extra project-oriented activities, and

2. OCB that is directed primarily at individuals within the organization, such as altruism and interpersonal helping.

A comparative analysis of four motivational bases of helping forms of OCB was conducted by Settoon (1997). The study performed in his research examined the relative influence of variables reflecting different views of helping behavior. The variables studied were: Instrumental Assistance, Support, and Need-Based Monitoring. The hypotheses for the motivational bases of OCB were as follows:

1. Employees who trust their coworkers will engage in helping forms of citizenship behavior.

2. Employees in central positions in informal organizational networks will engage in helping forms of citizenship behavior.

3. Employees who have received help from coworkers will engage in helping forms of citizenship behavior.

4. Employees with demanding jobs will reduce the amount of helping forms of citizenship behavior they engage in.

Settoon's results indicated that the importance of each variable in predicting helping behavior varied depending on the type of behavior being predicted. Although the degree of influence was stronger for some variables than others, each hypothesis was validated.

\section{LINKING KM AND OCB}

Important links exist between the two well-explored topics of KM and OCB. In general, the OCB findings indicate a correlation with the factors that inhibit KM. It is interesting to examine two of the facets of KM that mirror the two-factor model for OCB.

The first type of KM to fall short is that which relates to the organization. Most organizations utilize a traditional hierarchical business structure. With its definite distinction among management and employees, there is very little honest knowledge sharing (Nielsen 2004). For the most part, traditional leaders control information and monopolize decision-making. Nielsen (2004) explains that in a rank-based structure, managers are still "telling you that you have to contribute to a knowledge system." The result of this type of structure leads to behaviors of secrecy, distrust and being controlled. 
The second facet of KM examined is that of knowledge sharing between peers. Organizations must understand that effective KM between peers not only strengthens individual performance, but also strengthens the organizations as a whole. When peers feel free to share their ideas and experiential wisdom, learning curves for employees, as well as managers, are greatly shortened.

\section{SUGGESTED STRATEGIES TO IMPROVE KM WITHIN PM THROUGH OCB}

A foundation has been formed that indicates the relationship between OCB and those factors that motivate $\mathrm{KM}$. Based on existing research, we attempt to provide strategies for increased KM in PM based on those factors that OCB researchers have found to create a willingness for extra-role behaviors.

First, it was shown that trust is instrumental in fostering OCB. In order to produce environments that are conducive to trust and willful knowledge sharing, project organizations need to create innovative, non-threatening solutions. One possible solution might be to provide opportunities for social interaction. Greater social interaction may reduce feelings of mistrust. With an atmosphere of trust among project teams, the inhibition for knowledge sharing can be significantly reduced. It is also recommended that organizations create forums for sharing wisdom that utilize technology for idea documentation.

Second, it was shown that those who receive help will in turn provide social support. The solution here could be as simple as a reward system (financial motivation) for senior project managers who mentor younger project managers, or for documenting projects at completion. As stated by O'Dell (2004), "Behavior that is rewarded gets repeated."

Third, research has also shown that OCB, and subsequently KM, are influenced by those who have network centrality. In particular, those with expertise were shown to heavily influence instrumental assistance and social support. Many times, new project managers are unaware of those individuals who can be instrumental in providing assistance, expertise and competent advice. As a strategy for extracting the knowledge of these central employees, organizations should develop, and document as a service, positions for specific attainment of expertise.

Finally, the work of Settoon (1997) indicated that work overload served to reduce social support behavior. In project organizations, project teams will generally reduce the amounts of knowledge that they share in response to their own difficult performance goals and approaching deadlines. Therefore, it is important for organizations to establish fair and consistent guidelines for project workloads. Simply put, when faced with behavior choices, individuals will engage in those behaviors that are seen as less costly or more rewarding.

\section{CONCLUSIONS AND FUTURE RESEARCH}

Having gained insight into the study of KM through OCB, our work provides a theoretical foundation for the development of strategies that can enhance KM in the PM environment. As stated by Novins (2002), "The solution isn't creating the world's greatest database repository of all wisdom with the world's fanciest search engine. Instead, we need to give people specific tools designed to help them do their job and solve specific business problems." Hopefully, those in PM positions will be enlightened to see that they possess the knowledge to create situations that enhance not only their own performance, but the performance of their teams and colleagues, as well as the productivity of the organization as a whole. The theoretical correlations discussed here have provided the opportunity to continue this research and offer empirical evidence on the success of the proposed strategies. 


\section{REFERENCES}

1. Arens, W., Contemporary Advertising, 10 $0^{\text {th }}$ edition, McGraw-Hill/Irwin, New York City, NY, 2006.

2. Arrow, K., The Economic Implications of Learning by Doing, Review of Economic Studies, Vol. 29, June, pp. 155-173, 1962.

3. Burns, A. and R. Bush, Marketing Research, $5^{\text {th }}$ edition, Pearson/Prentice Hall, Upper Saddle River, NJ, 2006.

4. Dunn, J. and Neumeister, A., Knowledge Management in the Information Age, E-Business Review, Fall, pp. 37-45, 2002.

5. Gray, C. and Larson, E., Project Management: The Managerial Process, $3^{\text {rd }}$ edition, McGraw-Hill/Irwin, New York City, NY, 2006.

6. Koskinen, K., Knowledge Management to Improve Project Communication and Implementation, Project Management Journal, Vo.1. 35, 2-June, pp. 13-19, 2004.

7. Nielsen, J., The Myth of Leadership, Davies-Black Publishing, Mountain View, CA, 2004.

8. Novins, P., Knowledge Management for Competitive Advantage and Shareholder Value, E-Business Review, Fall, pp. 33-36, 2002.

9. O'Dell, C., The Executive's Role in Knowledge Management, American Productivity and Quality Center, Houston, TX, 2004.

10. Olson, D., Introduction to Information Systems Project Management, $2^{\text {nd }}$ edition, McGraw-Hill/Irwin, New York City, NY, 2004.

11. Organ, D., The Motivational Basis of Organizational Citizenship Behavior, Research in Organizational Behavior, Vol. 12, pp. 43-72, 1990.

12. Settoon, R., A Comparative Analysis of Four Motivational Bases of Helping Forms of Organizational Citizenship Behavior, Academy of Strategic and Organizational Leadership Journal, Vol. 1, No. 2, pp. 1-12, 1997.

13. Skarlicki, D. and Latham, G., Organizational Citizenship Behavior and Performance in a University Setting, Revue Canadienne des Sciences de l'Administration, September, pp. 22-33, 1995.

14. Stewart, T., The Corporate Jungle Spawns a New Species: The Project Manager, Fortune, September, pp 1415, 1996.

15. Wells, W., Burnett J. and Moriarty, S., Advertising: Principles \& Practice, $6^{\text {th }}$ edition, Prentice Hall, Upper Saddle River, NJ, 2003.

16. Wiig, K., Knowledge Management Foundations: Thinking about Thinking - How People and Organizations Create, Represent and Use Knowledge, Knowledge Management Series, Vol. 1, Schema Press, Arlington, TX, 1993.

17. Williams, L.J., and S. E. Anderson, Job Satisfaction and Organizational Commitment as Predictors of Organizational Citizenship and In-Role Behaviors, Journal of Management, Vol. 17, pp. 601-618, 1991. 


\section{NOTES}

